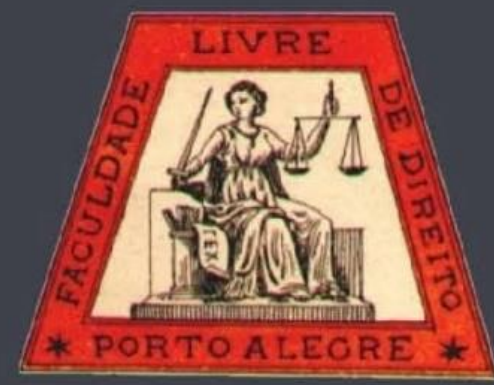

O Supremo Tribunal Federal e o processo legislativo constitucional - análise crítica da postura passivista procedimental adotada no julgamento do Mandado de Segurança $n^{\circ}$ 22.503-3/DF

The Supremo Tribunal Federal and the constitutional legislative process - critical analysis of the procedural passivist position adopted in the iudgment of the Mandado de Seguranca $n^{\circ} 22.503-3 / D F$

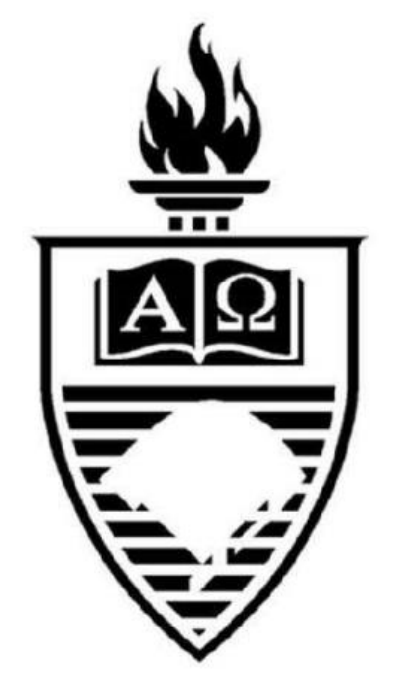

Adriana Campos Silva Universidade Federal de Minas Gerais

\title{
Rafael Costa de Souza
}

Universidade Federal de Minas Gerais

\section{UFRGS}


O Supremo Tribunal Federal e o processo legislativo constitucional: análise crítica da postura passivista procedimental adotada no julgamento do Mandado de Segurança $n^{0}$ 22.503-3/DF

\author{
The Supremo Tribunal Federal and the constitutional legislative process - critical analysis of the \\ procedural passivist position adopted in the judgment of the Mandado de Segurança $n^{\circ} 22.503-3 / D F$
}

Adriana Campos Silva*

Rafael Costa de Souza**

\title{
REFERÊNCIA
}

CAMPOS SILVA, Adriana; SOUZA, Rafael Costa de. O Supremo Tribunal Federal e o processo legislativo constitucional: análise crítica da postura passivista procedimental adotada no julgamento do Mandado de Segurança ${ }^{\circ}$ 22.503-3/DF. Revista da Faculdade de Direito da UFRGS, Porto Alegre, n. 36, p. 146-163, ago. 2017.

\begin{abstract}
RESUMO
O trabalho pretende analisar a postura passiva do Supremo Tribunal Federal diante os trâmites formais do Processo Legislativo brasileiro. Para atingir o objetivo final, será feita uma análise do julgamento paradigmático do Mandado de Segurança n ${ }^{\circ}$ 22.503-3/DF para demonstrar a postura passiva da Corte. Indo adiante, será feita uma revisão da literatura sobre as críticas contemporâneas à supremacia judicial para demonstrar que as críticas não justificam a postura deferente adotada pelo STF. Por fim, será feita uma crítica ao passivismo procedimental do Supremo Tribunal Federal em relação ao controle de processo legislativo democrático.
\end{abstract}

PALAVRAS-CHAVE

Supremo Tribunal Federal. Processo Legislativo. Interna corporis, Passivismo.

\section{ABSTRACT}

The paper intends to analyze the passive position of the Federal Supreme Court in the formal proceedings of the Brazilian Legislative Process. In order to reach the final objective, an analysis of the paradigmatic judgment of the Mandado de Segurança $n^{\circ} 22.503-3$ / DF will be made to demonstrate the passive position of the Court. Going forward, we will review the literature on contemporary criticism of judicial supremacy to demonstrate that criticism does not justify the deferential stance adopted by the Supreme Court. Finally, a critique will be made of the procedural passivity of the Federal Supreme Court in relation to the control of democratic legislative process.

\section{KEYWORDS}

Federal Court of Justice. Legislative process. Interna corporis. Passivism

\section{SUMÁRIO}

Introdução. 1. O processo legislativo e o controle preventivo de constitucionalidade do supremo tribunal federal. 2. A vedação do controle de constitucionalidade sobre os atos interna corporis e o julgamento do mandado de segurança $\mathrm{n}^{\circ}$ 22.503-3/DF. 2.1. Voto do ministro relator Marco Aurélio. 2.2. Posição vencedora capitaneada pelo ministro Maurício Corrêa. 3. Análise do julgamento do mandado de segurança $\mathrm{n}^{\circ}$ 22.503-3/DF e a postura passivista do Supremo Tribunal Federal. 3.1. Questões conceituais e procedimentais prevista no Regimento Interno da Câmara dos Deputados. 3.2. O passivismo procedimental adotado no julgamento. 4. Passivismo procedimental do Supremo Tribunal Federal em relação ao processo legislativo constitucional. 5. Crítica ao passivismo procedimental adotado pelo Supremo Tribunal Federal no julgamento do mandado de segurança $n^{\circ} 22.503$. Conclusão. Referências.

\footnotetext{
* Professora de Direito Constitucional da Universidade Federal de Minas Gerais (UFMG), em nível de graduação e pósgraduação. Doutora em Direito (UFMG, 2002). Mestre em Direito (UFMG, 1990). Especialista em Direito Internacional, América Latina e Caribe (United Nations Institute for Training and Research, 1988). Graduada em Direito (UFMG, 1985). ** Professor do Centro Universitário Newton Paiva. Mestrando em Direito Político (Universidade Federal de Minas Gerais - UFMG, desde 2015). Pós-graduado em Direito Constitucional pelo Instituto para o Desenvolvimento Democrático (em parceria com a Universidade de Coimbra, Portugal). Graduado em Direito (UFMG, 2013). Advogado.
} 


\section{INTRODUÇÃO}

Desde a promulgação da Constituição da República de 1988, tem se observado um constante e progressivo avanço do fenômeno da judicialização da política no cenário institucional brasileiro. Cada vez mais, o Supremo Tribunal Federal tem se deslocado para o centro do sistema político nacional.

Ao lado desse fenômeno, ressurge o clássico dilema da "dificuldade contramajoritária" posto por Alexander Bickel na obra "The Least Dangerous Branch: The Supreme Court at de Bar of Politics".

É certo que após passar um por forte período de entusiasmo doutrinário, a "supremacia judicial" tem sido alvo de uma forte desconfiança, o que tem levado ao questionamento do papel das cortes constitucionais e dos fundamentos do judicial review.

A recente experiência brasileira tem apresentado algumas peculiaridades a serem analisadas. O Supremo Tribunal Federal tem sido constantemente provocado para interferir no processo legislativo. Uma das polêmicas enfrentadas pelo Judiciário brasileiro é a interferência nas questões interna corporis e especificamente sobre o manejo das emendas aglutinativas durante o trâmite das propostas de emendas constitucionais.

O Supremo Tribunal Federal tem assentado o entendimento da possibilidade do controle judicial preventivo de constitucionalidade a fim de assegurar ao parlamentar o direito subjetivo ao processo legislativo constitucional. No entanto, a Corte tem entendido que não cabe controle em relação aos atos políticos e aos atos interna corporis do parlamento, o que significaria uma proibição à interpretação das normas regimentais. Este entendimento foi consolidado quando do julgamento paradigmático do Mandado de Segurança $n^{\circ}$ 22.503-3/DF que questionava o trâmite da Proposta de Emenda Constitucional $n^{\circ}$
33/95 que modificou o sistema da Previdência Social.

No presente trabalho, vamos analisar a postura passivista adotada pelo Corte Suprema quando do referido Mandado de Segurança.

É importante registrar que o "passivismo" do Supremo Tribunal Federal não deve ser entendido num sentido denotativo. Trabalharemos com a expressão "passivismo" no sentido de categorizar a postura deferente do Supremo Tribunal Federal ao Poder Legislativo ao se esquivar de realizar o efetivo o controle de constitucionalidade sobre o processo legislativo, como demonstraremos ao longo do trabalho.

\section{O PROCESSO LEGISLATIVO E O CONTROLE PREVENTIVO DE CONSTITUCIONALIDADE DO SUPREMO TRIBUNAL FEDERAL}

A relação institucional entre Parlamento e Judiciário tem ganhado um contorno peculiar no Brasil. O Supremo Tribunal Federal tem sido provocado pelos próprios parlamentares a deliberar sobre questões atinentes à vida política do Congresso Nacional.

Um dos pontos polêmicos a ser decidido se refere às questões internas corporis, e, especificamente, em relação ao manejo das emendas aglutinativas durante o trâmite das propostas de emenda à constituição.

Em duas recentes situações - Proposta de Emenda Constitucional $n^{\circ} 182 / 2007$, sobre a Reforma Política, e a P.E.C. no 171/1993, sobre a redução da maioridade penal -, o país assistiu uma mudança drástica no resultado das votações do Plenário da Câmara dos Deputados em menos de 24 horas.

Em meio à crise institucional vivida pelo Legislativo, o Supremo Tribunal Federal tem sido 
constantemente chamado a decidir sobre o processo legislativo. ${ }^{1}$

O Supremo Tribunal Federal tem assentado o entendimento de que é cabível o controle de constitucionalidade preventivo quando o processo legislativo viola a Constituição da República. O argumento utilizado é o de que o parlamentar tem o direito de participar de um processo legislativo constitucional. $^{2}$

Este entendimento foi firmado no seguinte leading case $^{3}$ :

\begin{abstract}
Mandado de segurança contra ato da Mesa do Congresso que admitiu a deliberação de proposta de emenda constitucional que a impetração alega ser tendente a abolição da república. - Cabimento do mandado de segurança em hipóteses em que a vedação constitucional se dirige ao próprio processamento da lei ou da emenda, vedando a sua apresentação (como é o caso previsto no parágrafo único do artigo 57) ou a sua deliberação (como na espécie). Nesses casos, a inconstitucionalidade diz respeito ao próprio andamento do processo legislativo, e isso porque a Constituição não quer em face da gravidade dessas deliberações, se consumadas - que sequer se chegue a deliberação, proibindo-a taxativamente. A inconstitucionalidade, se ocorrente, já existe antes de o projeto ou de a proposta se transformar em lei ou em emenda constitucional, porque o próprio processamento já desrespeita, frontalmente, a constituição. Inexistência, no caso, da pretendida inconstitucionalidade, uma vez que a prorrogação de mandato de dois para quatro anos, tendo em vista a conveniência da coincidência de mandatos nos vários níveis da Federação, não implica introdução do princípio de que os mandatos não mais são
\end{abstract}

\footnotetext{
${ }^{1}$ Segundo levantamento feito pelo site "G1" do Grupo Globo, nos dois primeiros anos da 55 a Legislatura (20152019), o Congresso Nacional provocou 45 (quarenta e cinco) vezes o Supremo Tribunal Federal para interferir no processo legislativo. Disponível em: <http://g1.globo.com/politica/noticia/em-2-anosparlamentares-questionam-decisoes-do-congresso-45vezes-no-stf.ghtml>. Acesso em: 24 abr. 2017.

2 Vide: MS 24.642, Rel. Min. Carlos Velloso, DJ de 18.6.2004; MS 20.452/DF, Rel. Min. Aldir Passarinho, RTJ, 116 (1)/47; MS 21.642/DF, Rel. Min. Celso de Mello, RDA, 191/200; MS 24.645/DF, Rel. Min. Celso de Mello, DJ de 15.9.2003; MS 24.593/DF, Rel. Min. Maurício Corrêa, DJ de 8.8.2003; MS 24.576/DF, Rel. Min. Ellen Gracie, DJ de 12.9.2003; MS 24.356/ DF, Rel. Min. Carlos Velloso, DJ de 12.9.2003.
}

temporários, nem envolve, indiretamente, sua adoção de fato. Mandado de segurança indeferido. ${ }^{4}$

Assim, o Supremo Tribunal Federal tem admitido o controle preventivo por via incidental e conhecido mandados de seguranças impetrados por parlamentares contra o processamento de propostas de emendas à Constituição que violem o artigo $60, \S 4^{\circ}$, sob o argumento da possibilidade de fiscalização jurisdicional de constitucionalidade de propostas de emendas que deliberarem sobre matéria vedada ao poder reformador do Congresso Nacional. ${ }^{5}$

\section{A VEDAÇÃO DO CONTROLE DE CONSTITUCIONALIDADE SOBRE OS ATOS INTERNA CORPORIS E O JULGAMENTO DO MANDADO DE SEGURANÇA N 22.503-3/DF}

Se por um lado, o Supremo Tribunal Federal tem assentado o entendimento do controle judicial preventivo de constitucionalidade a fim de assegurar ao parlamentar o direito ao processo legislativo constitucional, de outro ele tem entendido que não cabe controle em relação aos atos políticos e aos atos interna corporis do parlamento, o que significaria uma proibição à interpretação das normas regimentais. Este entendimento foi consolidado no julgamento

${ }^{3}$ Esta decisão serviu de paradigma para outras decisões, como por exemplo: MS 21754 AgR, Relator(a): Min. Marco Aurélio, Relator(a) p/ Acórdão: Min. Francisco Rezek, Tribunal Pleno, julgado em 07/10/1993; MS 21648, Relator(a): Min. Octavio Galotti, Relator(a) p/ Acórdão: Min. Ilmar Galbão, Tribunal Pleno, julgado em 05/05/1993; MS 22183, Relator(a): Min. Marco Aurélio, Relator(a) p/ Acórdão: Min. Maurício Correa, Tribunal Pleno, julgado em 05/04/1995.

4 BRASIL. Supremo Tribunal Federal. Mandado de Segurança $n^{\circ}$ 20.257. Relator: Ministro Décio Miranda, relator para acórdão Ministro Moreira Alves. Brasília, 08 de outubro de 1980. Diário da Justiça. Brasília, 27 fev. 1981.

5 BARROSO, Luís Roberto. $O$ controle de constitucionalidade no direito brasileiro: exposição sistemática da doutrina e análise crítica da jurisprudência. 6. ed. São Paulo: Saraiva, 2012. p. 48. 
paradigmático do Mandado de Segurança $\mathrm{n}^{\circ}$ 22.503-3/DF.

O contexto histórico do Mandado de Segurança $\mathrm{n}^{\circ}$ 22.503-3/DF gira em torno da aprovação da Proposta de Emenda Constitucional $n^{\circ} 33 / 95$ que tinha como objeto a modificação do sistema da Previdência Social. A PEC no 33/95 originou-se do desmembramento da Proposta $n^{\circ}$ 25/95 e após a tramitação legislativa recebeu parecer favorável da Comissão de Constituição e Justiça da Câmara dos Deputados e logo após foi designada a Comissão Especial para apreciação da matéria. Com o término do prazo previsto no Regimento, o Presidente da Câmara nomeou o relator, Deputado Euler Riberito, em substituição à Comissão Especial para que a matéria fosse apreciada pelo Plenário.

Em 06.03.1996, o substitutivo apresentado pelo Relator foi rejeitado pelo Plenário. Após o substitutivo ter sido rejeitado, o então Presidente da Câmara, Luís Eduardo Magalhães, designou o Deputado Michel Temer como novo relator da matéria. Em 21 de março de 1996, a Câmara aprovou a Emenda Aglutinativa ${ }^{\circ}$ 6, que fundia parte dos textos da PEC n ${ }^{\circ} 33 / 95$ com as emendas oferecidas pela Comissão Especial.

Em 11 de abril de 1996, vários Deputados impetraram Mandado de Segurança contra ato do Presidente da Câmara, alegando que o Deputado Michel Temer havia sido o autor da Emenda Aglutinativa $\mathrm{n}^{\circ} 6$, o que ensejaria violação aos artigos 43 , parágrafo único, $118, \S 3^{\circ}, 163$, inciso VI, artigo 17, I, r, todos do Regimento Interno da Câmara dos Deputados:

Art. 43. Nenhum Deputado poderá presidir reunião de Comissão quando se debater ou votar matéria da qual seja Autor ou Relator.

Parágrafo único. Não poderá o Autor de proposição ser dela Relator, ainda que substituto ou parcial.
Art. 118. Emenda é a proposição apresentada como acessória de outra, sendo a principal qualquer uma dentre as referidas nas alíneas $a$ a $e$ do inciso I do art. 138. [...] $\S 3^{\circ}$ Emenda aglutinativa é a que resulta da fusão de outras emendas, ou destas com o texto, por transação tendente à aproximação dos respectivos objetos.

Art. 163. Consideram-se prejudicados: [...] IV - a discussão ou a votação de proposição apensa quando a rejeitada for idêntica à apensada;

Art. 17. São atribuições do Presidente, além das que estão expressas neste Regimento ou decorram da natureza de suas funções e prerrogativas: I - quanto às sessões da Câmara: [...] r) anunciar o resultado da votação e declarar a prejudicialidade. ${ }^{6}$

Além disso, os impetrantes aduziam que o texto da Emenda Aglutinativa reproduzia em grande parte a proposta encaminhada pelo Poder Executivo para a Comissão Especial e que a reapreciação da matéria ensejaria violação ao art. $60, \S 5^{\circ}$, da Constituição da República.

\subsection{Voto do ministro Marco Aurélio}

Quando do julgamento do Mandado de Segurança no 22.503-3, o Ministro Marco Aurélio explicou que a apreciação da emenda aglutinativa se deu intempestivamente após a apreciação e rejeição da proposição inicial: “[...] no caso, procedeu-se à apreciação de emenda aglutinativa quando já apreciada e rejeitada a proposição inicial. Mais do que isso, implementou-se a prática em data diversa daquela em que teve início a votação"?

No seu voto, o Ministro Relator entendeu que o texto da Emenda Aglutinativa não ficou restrito as emendas apresentadas, valendo-se de trechos da emenda encaminhada pelo Poder Executivo e que supostamente estavam prejudicadas em razão da matéria ter sido rejeitada quando da apreciação do substitutivo

7 BRASIL. Supremo Tribunal Federal. Mandado de Segurança $n^{\circ}$ 22.503. Relator: Relator Ministro Marco Aurélio, Relator para o Acórdão Ministro Maurício Corrêa. Brasília, DF, 08 de maio de 1996. Diário da Justiça. Brasília, 06 jun. 1997. p. 521. 
pelo Plenário. ${ }^{8} \mathrm{O}$ Ministro Marco Aurélio argumentou que a apreciação do substitutivo em Plenário prejudicou a apreciação da matéria e por isso a Emenda Aglutinativa não poderia ter sido deliberada naquela sessão legislativa nos termos do preceito do artigo $60, \S 5$, da Constituição da República.

\begin{abstract}
A par dessas condições, de todo inafastáveis, tem-se ainda que o $\S 5^{\circ}$ é categórico ao revelar que a matéria constante de proposta de emenda rejeitada ou havida por prejudicada não pode ser objeto de nova proposta na mesma sessão legislativa. Implica dizer que a conclusão sobre a rejeição da proposta inicialmente formulada e que motivou, desta ou daquela forma, a deliberação do Plenário da Câmara dos Deputados somente poderia ser reapresentada na sessão legislativa de 1997. O preceito constitucional é de clareza solar. Alude não à reapresentação de proposta, nas à impossibilidade de ser apreciada matéria - gênero - constante de proposição de emenda rejeitada ou havida por prejudicada. A referência à matéria tem o fim de evitar que, à mercê de sutis alterações na proposta, possa-se chegar ao drible à vedação constitucional. ${ }^{9}$
\end{abstract}

Então, o Ministro Marco Aurélio concluiu que a norma rotulada de "emenda aglutinativa", na verdade se tratava de uma nova proposição e por isso a matéria não poderia ter sido apreciada pelo Plenário sob pena de violação da vedação constitucional. ${ }^{10}$

\subsection{Posição vencedora capitaneada pelo ministro Maurício Corrêa}

Com exceção do Ministro Marco Aurélio, todos os magistrados acompanharam o voto do Ministro Maurício Corrêa para indeferir a segurança.

O Ministro Maurício Correa se limitou a dizer que a rejeição do substitutivo não enseja a rejeição da proposição original, o que permitiria o trâmite e deliberação do projeto principal. ${ }^{11}$
No mesmo sentido, o Ministro Francisco Rezek entendeu que a emenda aglutinativa não se tratava de uma nova proposta, o que não prejudica a continuidade das discussões em torno da proposição original e por isso não haveria ofensa ao parágrafo $5^{\circ}$ do artigo 60 da Constituição. ${ }^{12}$

Por sua vez, o Ministro Ilmar Galvão recorreu ao Regimento Interno da Câmara dos Deputados, fundamentando que o processo legislativo da referida emenda constitucional não havia terminado, visto que a rejeição do substitutivo não se confunde com a rejeição da proposição original. ${ }^{13}$ Indo além, o Ministro Ilmar Galvão enfrentou a questão de que a emenda aglutinativa reproduzia em grande parte o conteúdo do substitutivo rejeitado, afirmando que as reproduções são naturais no processo legislativo e que não há vedação no regimento para tal prática. ${ }^{14}$

Os Ministros Carlos Veloso, Celso de Mello, Octavio Gallotti, Sydney Sanches, Neri da Silveira e Sepúlveda Pertence também fundamentaram sua decisão seguindo o mesmo entendimento de que a rejeição do substitutivo não enseja a rejeição do original, sendo que o processo legislativo ainda não havia finalizado. ${ }^{15}$

A maioria dos Ministros do Supremo entendeu que não houve ofensa ao art. $60, \S 5^{\circ}$, da Constituição da República, porque a rejeição do substitutivo não prejudica a continuidade do processo de tramitação legislativa da proposição original.

\section{ANÁLISE DO JULGAMENTO DO MANDADO DE SEGURANÇA $\mathbf{N}^{\circ}$ 22.503- 3/DF E A POSTURA PASSIVISTA DO SUPREMO TRIBUNAL FEDERAL}

\footnotetext{
${ }^{8}$ Ibid.

${ }^{9}$ Ibid, p. 522.

${ }^{10}$ Ibid, p. 527.

${ }^{11}$ Ibid, p. 529.
}

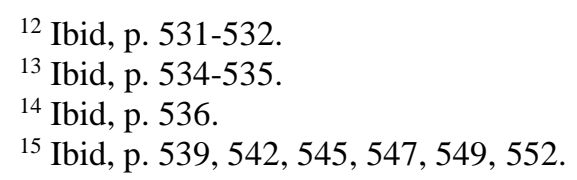


3.1 Questões conceituais e procedimentais prevista no Regimento Interno da Câmara dos Deputados

Para entender a questão que circunda o Mandado de Segurança 22.503-3/DF é preciso esclarecer algumas questões conceituais e procedimentais do Processo Legislativo previstas no Regimento Interno da Câmara dos Deputados (RICD).

Segundo o artigo 100 do RICD, proposição legislativa é toda matéria sujeita a deliberação na Câmara, sendo que as "proposições poderão consistir em proposta de emenda à Constituição, projeto, emenda, indicação, requerimento, recurso, parecer e proposta de fiscalização $e$ controle". ${ }^{16}$

O capítulo V do título IV do Regimento Iinterno ainda dispõe sobre as Emendas, sendo que o artigo $118, \S \S 3^{\circ}$ e $4^{\circ}$, dá os conceitos de emendas aglutinativas e substitutivas (denominada "substitutivo"):

Art. 118. Emenda é a proposição apresentada como acessória de outra, sendo a principal qualquer uma dentre as referidas nas alíneas $a$ a $e$ do inciso I do art. 138.

$\S 1^{\circ}$ As emendas são supressivas, aglutinativas, substitutivas, modificativas ou aditivas. [...]

$\S 3^{\circ}$ Emenda aglutinativa é a que resulta da fusão de outras emendas, ou destas com o texto, por transação tendente à aproximação dos respectivos objetos.

$\S 4^{\circ}$ Emenda substitutiva é a apresentada como sucedânea a parte de outra proposição, denominando-se "substitutivo" quando a alterar, substancial ou formalmente, em seu conjunto; considera-se formal a alteração que vise exclusivamente ao aperfeiçoamento da técnica legislativa. ${ }^{17}$

Observa-se da norma regimental que as emendas, tanto as substitutivas como as aglutinativas, têm natureza acessória à proposição principal.
Conforme ensina o professor da USP, Carlos Bastide Horbach, ao analisar a polêmica a aprovação da PEC da redução da maioridade penal para a revista eletrônica Consultor Jurídico, as emendas - inclusive o substitutivo - tem natureza acessória e explica que, segundo o inciso V do artigo 191 do Regimento, a rejeição do substitutivo faz com que a proposição inicial (principal) seja votada, devendo-se observar a precedência na apreciação das emendas que tenham sido apresentadas. ${ }^{18}$

O Regimento Interno ainda prevê que havendo várias emendas à proposta inicial é possível a reunião dos textos numa emenda aglutinativa, nos termos do citado parágrafo $3^{\circ}$ do artigo 118. A partir da leitura do artigo 122 do RICD infere-se que as emendas aglutinativas podem ser apresentadas em Plenário, quando da votação da proposição.

\subsection{O passivismo procedimental adotado no julgamento}

Feitas estas considerações, em que pese o entendimento dos Ministros, acreditamos que as duas posições - tanto a majoritária, como a do Ministro Marco Aurélio - se equivocaram ao apreciar o mérito da questão levada ao Supremo Tribunal Federal.

Observa-se que o Ministro Marco Aurélio se equivocou ao confundir a votação do substitutivo com a proposta inicial, o que prejudicaria a reapreciação da matéria. Ressaltase o equívoco do Relator: "[...] no caso, procedeu-se à apreciação de emenda aglutinativa quando já apreciada e rejeitada a proposição inicial. Mais do que isso, implementou-se a

\footnotetext{
${ }^{16}$ BRASIL. Congresso Nacional. Câmara dos Deputados. Regimento interno da Câmara dos Deputados [recurso eletrônico]. 15. ed. Brasília: Câmara dos Deputados, Edições Câmara, 2015. (Série textos básicos, n. 103).
}

\footnotetext{
${ }^{17}$ Ibid.

${ }^{18}$ HORBACH, Carlos Bastide. Por que a aprovação da PEC da maioridade penal é constitucional. Consultor Jurídico. 05 jul. 2015.
} 
prática em data diversa daquela em que teve início a votação". ${ }^{19}$

O que foi levado à Plenário no dia 06 de março de 1993 foi o substitutivo e não a proposição original de Emenda à Constituição. Após a rejeição do Substitutivo, o Regimento Interno prevê que a continuidade da tramitação em relação a proposição original e emendas.

Por outro lado, o Ministro Marco Aurélio foi preciso ao afirmar que a Emenda Aglutinativa $\mathrm{n}^{\mathrm{o}} 6$ foi apresentada intempestivamente, visto que segundo o art. 122 do RICD, elas deveriam ser apresentadas Plenário quando da apreciação da proposição, sendo que, de fato, a emenda aglutinativa só foi deliberada vinte dias depois.

De outro giro, a posição majoritária liderada pelo Ministro Maurício Côrrea foi correta ao apontar o equívoco de interpretação do Regimento Interno do Relator. Frisa-se que a rejeição do substitutivo não prejudica a continuidade da tramitação da proposição original e da apreciação das emendas - a rejeição do acessório não prejudica o principal.

No entanto, a maioria do Supremo Tribunal Federal perdeu a oportunidade de interpretar o Regimento Interno conforme a Constituição ao se abster de enfrentar as questões regimentais.

4 PASSIVISMO PROCEDIMENTAL DO SUPREMO TRIBUNAL FEDERAL EM RELAÇÃO AO PROCESSO LEGISLATIVO CONSTITUCIONAL

\section{No julgamento da Ação Direta de} Inconstitucionalidade $\mathrm{n}^{\mathrm{o}} 4.425$ - que versava sobre a constitucionalidade formal da Emenda

19 BRASIL. Supremo Tribunal Federal. Mandado de Segurança $\mathrm{n}^{\circ}$ 22.503. Relator: Relator Ministro Marco Aurélio, Relator para o Acórdão Ministro Maurício Corrêa. Brasília, DF, 08 de maio de 1996. Diário da Justiça. Brasília, 06 jun. 1997. p. 521.

20 BRANDÃO, Rodrigo. Supremacia judicial versus diálogos institucionais: a quem cabe a última palavra sobre o sentido da constituição. Rio de Janeiro: Lumen Juris, 2012. p. 370.
Constitucional $n^{\circ}$ 62/2009, conhecida como Emenda dos Precatórios -, o ministro relator Luiz Fux para fundamentar a posição que o Supremo Tribunal Federal não deve interferir nas questões internas parlamentares, salvo quando houver violação expressa à constituição, argumentou em favor de uma "deferência" ao Poder Legislativo no que diz respeito às questões interna corporis em razão do valor democrático do processo político e da necessidade de adoção de uma postura dialógica ${ }^{20}$ na solução das controvérsias constitucionais, evitando uma supremacia judicial em relação aos demais poderes:

Em suma, parece-me que esta Suprema Corte não
pode se arvorar à condição de juiz da robustez do
debate parlamentar para além das formas
expressamente exigidas pela Constituição Federal.
No que excede os limites constitucionais, há que se
reconhecer uma espécie de deferência à atuação do
Poder Legislativo no campo dos atos formais que se
inserem no processo político, dotadas de um valor
intrínseco pelo batismo democrático também no que
concerne à interpretação da Constituição. É tênue,
com efeito, o limite entre a defesa judicial dos
valores da Constituição, missão irrenunciável deste
Supremo Tribunal Federal por força da própria Carta
de 1988 (CF, art. 102, caput), e uma espécie perigosa
de supremacia judicial, através da qual esta Corte
acabe por negar qualquer voz aos demais poderes
políticos na construção do sentido e do alcance das
normas constitucionais. ${ }^{21}$

Observa-se que a postura passivista do Supremo Tribunal Federal tem sido justificada na desconfiança da supremacia judicial - entendida como a prerrogativa do Judiciário em dar a última palavra sobre o sentido das normas constitucionais. $^{22}$

De fato, apesar do avanço da jurisdição constitucional no último século, a doutrina

21 BRASIL. Supremo Tribunal Federal. Ação Direta de Inconstitucionalidade $\mathrm{n}^{\circ}$ 4.425, Distrito Federal. Relator: MInistro Ayres Brito, redator para Acórdão Ministro Luiz Fux. Brasília, 14 de março de 2013. Diário da Justiça Eletrônico. Brasília, 19 dez. 2013. Disponível em: <http://redir.stf.jus.br/paginadorpub/paginador.jsp?docTP= TP\&docID=5067184>. Acesso em: 25 abr. 2017. p. 58 22 BRANDÃO, op. cit., p. 15. 
constitucional vive um momento de desconfiança em relação à "supremacia judicial" na interpretação da Constituição. ${ }^{23}$

Longe de ser um problema exclusivo da realidade brasileira, o certo é que sempre que as Supremas Cortes julgam uma questão polêmica da vida política ressurge o clássico dilema da "dificuldade contramajoritária" e da legitimidade democrática do controle de constitucionalidade posto por Alexander Bickel na obra "The Least Deangerous Branch: The Supreme Court at de Bar of Politics". ${ }^{24}$

A tensão entre Democracia e Constituição sempre foi objeto de estudo da teoria constitucional. No entanto, ela tem sido revista pela doutrina, e mais especificamente por algumas escolas norte-americanas. Nimer Sultany divide esses autores a partir da seguinte classificação $^{25}$ :

(i) "negadores": pois negam a tensão (ex: Ronald Dworkin, Bruce Ackerman e Frederick Schauer);

(ii) "reconciliadores": uma vez que reconciliam a tensão (ex: John Hart Ely, Cass Sunstein e Larry Kramer);

(iii) "endossadores": eles reconhecem que não há como reconciliar a tensão, mas endossam do mesmo jeito (ex: Frank Michelan, Louis Seidman e Laurence Triber);

(iv) "dissolvedores": eles dissolvem a tensão através da renúncia da jurisdição constitucional em favor da validade da legislação (ex: Jeremy Waldron, Richard Parker and Mark Tushnet). ${ }^{26}$

\footnotetext{
${ }^{23}$ BUSTAMANTE, Thomas da Rosa; BUSTAMANTE, Evanilda Nascimento de Godoi. Jurisdição Constitucional na era cunha: entre o passivismo procedimental e o ativismo substancialista do Supremo Tribunal Federal. Revista Direito \& Práxis. Rio de Janeiro, v. 07, n. 13, 2016. p. 350. ${ }^{24}$ BICKEL, Alexander M. The least dangerous branch: the supreme court at the bar of politics. Indianapolis, New York: The Bobbs-Merrill Company, 1962. p. 16.

${ }^{25}$ SULTANY, N. The State of Progressive Constitutional Theory: The Paradox of Constitutional Democracy and the Project of Political Justification. Harvard Civil Rights Civil Liberties Law Review, 47/2012. p. 377.

${ }^{26}$ Tradução livre de: “(i) "deniers”- because they deny the tension (e.g., Ronald Dworkin, Bruce Ackerman, and Frederick Schauer); (ii) "reconcilers"-because they reconcile the tension (e.g., John Hart Ely, Cass Sunstein,
}

Assim, apesar da permanente desconfiança e preocupação em relação aos Poderes Legislativo e Executivo, o Judiciário também tem sido alvo de questionamentos. Luís Roberto Barroso divide as críticas à expansão da intervenção judicial em três blocos: $:^{27}$

(i) Crítica político-ideológica: que questiona o déficit democrático das decisões dos magistrados - agentes públicos não eleitos - em relação às decisões de agentes eleitos democraticamente. Na teoria constitucional, este problema foi denominado dificuldade contra majoritária por Alexander Bickel na clássica obra "The Least Dangerous Branch: The Supreme Court at de Bar of Politics". ${ }^{28}$

(ii) Crítica quanto à capacidade institucional: para Cass Sunstein e Adrian Vermeule $^{29}$, o Poder Judiciário não é a instância adequada para dar a última palavra em determinadas matérias de extrema complexidade, sobretudo sobre temas envolvendo aspectos científicos e técnicos ou que envolva riscos de efeitos sistêmicos imprevisíveis e indesejáveis pelo magistrado.

(iii) Crítica quanto à limitação do debate: este corrente critica a elitização do debate judicial, visto que o judicial review acaba por gerar um déficit democrático ao retirar a deliberação da esfera pública por excelência (Legislativo) - local onde as razões podem ser debatidas de forma clara

and Larry Kramer); (iii) "endorsers"-because they recognize the irreconcilability of the tension yet endorse it (e.g., Frank Michelman, Louis Seidman, and Laurence Tribe); or (iv) "dissolvers"-because they dissolve the tension by forgoing judicial review of the validity of legislation (e.g., Jeremy Waldron, Richard Parker, and Mark Tushnet)".

${ }^{27}$ BARROSO, Luís Roberto. Constituição, democracia e supremacia judicial: direito e política no Brasil contemporâneo. RFD - Revista da Faculdade de Direito $U E R J$, v.2, n. 21, jan./jun. 2012. p. 10.

${ }^{28}$ BICKEL, op. cit., p. 16.

29 SUNSTEIN, Cass R; VERMEULE, Adrian. Interpretation and institutions. John M. Olin Program in Law and Economics Working Paper No. 156, 2002. 
e abrangente - e transferir para os tribunais locais técnicos e formais. ${ }^{30}$

Daniel Sarmento explica que as críticas à expansão judicial oscilam a partir de acordo com as posições políticas adotas pelos tribunais, sendo que a experiência norte-americana é bastante ilustrativa:

\begin{abstract}
Nos Estados Unidos, esta dinâmica é facilmente perceptível. Nas primeiras décadas do século passado, quando a Suprema Corte adotava posição política conservadora, limitando seriamente a possibilidade de o Estado atuar no mercado e na sociedade em favor dos interesses dos grupos mais fracos, a crítica era capitaneada por juristas e políticos situados à esquerda do espectro político, que defendiam a autocontenção judicial. Quando, após a década de 50, o ativismo jurisdicional voltouse à defesa de direitos fundamentais de minorias, como os negros e presos, e à tutela de liberdades nãoeconômicas, a crítica passa a ser esboçada a partir da direita, com os originalistas. E nos últimos tempos, em que a Suprema Corte vem caminhando a passos largos para o flanco conservador, foram juristas de esquerda que passaram a contestar a judicial review, elaborando a teoria do chamado 'constitucionalismo popular'. Com esta constatação, não se pretende negar a sinceridade dos críticos, nem tampouco desmerecer os seus argumentos, mas apenas mostrar como este tema, como tanto outros do debate constitucional, nunca é plenamente dissociável da política. $^{31}$
\end{abstract}

A justificação da jurisdição constitucional, sobretudo no que diz respeito a temas típicos da vida política, tem sido revistas pelas teorias normativas e descritivas dos modelos de comportamento dos magistrados.

Em relação às teorias normativas, ao contrário do que há muito tem se defendido, os hard cases não são simplesmente solucionados à luz dos princípios da proporcionalidade e da razoabilidade a partir de um sopesamento de princípios constitucionais. ${ }^{32} \mathrm{~A}$ natureza vaga e aberta das normas constitucionais acabar por conferir ao intérprete um poder criativo, constituindo a conhecida crítica de que os juízes detém um poder constituinte permanente - o que seria uma carta branca para que eles interpretassem o texto constitucional a partir dos seus valores pessoais e de suas preferências políticas. $^{33}$

Além dos problemas relativos à linguagem da norma constitucional, a doutrina tem identificado que existe um desacordo constante, substancial e de boa-fé entre os membros da sociedade sobre o sentido das normas - os desacordos morais razoáveis. ${ }^{34}$ Alguns autores também têm apontado que as Constituições, enquanto documentos pluralistas, muitas vezes, consagram valores diversos e que nos casos concretos acabam por entra em rota de colisão ${ }^{35}$ crítica que leva novamente a conclusão de que nos hard cases, o sentido da norma, em última análise, será sempre determinado pelo julgador. E, tendo em vista que o Direito não apresenta soluções préprontas, o julgamento sempre exigirá uma atuação criativa por parte do intérprete, que não raro, deverá recorrer a elementos externos ao Direito, como as filosofias moral e política, além de precisar escolher um método interpretativo específico, sendo que os magistrados acabam por

substancialista do Supremo Tribunal Federal. Revista Direito \& Práxis. Rio de Janeiro, v. 07, n. 13, 2016. p. 350. ${ }^{33}$ SARMENTO; NETO, op. cit., p. 127.

${ }^{34}$ WALDRON, Jeremy. Law and Disagreement. New York: Oxford University Press, 1999; WALDRON, Jeremy. The core of the case against judicial review. Yale Law Journal, v. 115, p. 1346-1406, 2006.

${ }^{35}$ BARROSO, Luís Roberto. Constituição, democracia e supremacia judicial: direito e política no Brasil contemporâneo. RFD - Revista da Faculdade de Direito $U E R J$, v.2, n. 21, jan./jun. 2012. p. 24. 
escolher métodos diversos a partir de critérios pessoais. ${ }^{36}$

Somado a isso, as análises dos comportamentos dos juízes têm demonstrado empiricamente às circunstâncias políticas que influenciam os julgamentos, colocando em xeque vários dogmas jurídicos, como por exemplo, a independência do Judiciário e vinculação do juiz ao sistema jurídico na tomada de decisões. ${ }^{37}$

As teorias descritivas têm demonstrado que o Direito não é aquele modelo normativo imaginado de um sistema de regras e princípios de onde o juiz apolítico e imparcial extrai as soluções para os conflitos sociais de forma autônoma e independente. Novamente, leva-se a conclusão de que os julgamentos acabam por refletir as ideologias pessoais dos magistrados que são influenciadas por inúmeros fatores políticos, ao ponto de alguns afirmarem que as soluções dos hard cases serão, em última análise, àquelas que atendam as preferências pessoais, as ideologias ou a fatores externos ao Direito, como as questões institucionais. ${ }^{38}$

Assim, para essas teorias, além das contribuições das teorias normativas (deve ser) que se preocupam como os juízes devem julgar -, a justificação do judicial review deve levar em conta como de fato os juízes julgam (ser), levando em consideração: i) os valores e ideologia do juiz; ii) as interações internas da corte; iii) as interações

\footnotetext{
${ }^{36}$ BARROSO, Luís Roberto. Constituição, democracia e supremacia judicial: direito e política no Brasil contemporâneo. RFD - Revista da Faculdade de Direito $U E R J$, v.2, n. 21, jan./jun. 2012. p. 25.

${ }^{37}$ FRIEDMAN, Barry. The Politics of judicial review. New York University Public Law and legal theory working papers. Paper 16. 2006.

${ }^{38}$ BARROSO, Luís Roberto. Constituição, democracia e supremacia judicial: direito e política no Brasil contemporâneo. RFD - Revista da Faculdade de Direito UERJ, v.2, n. 21, jan./jun. 2012, p.27.

${ }^{39}$ FRIEDMAN, Barry. The politics of judicial review. New York University Public Law and Legal Theory Working Papers. Paper 16, 2006; FRIEDMAN, Barry. The will of the people: how public opinion has influenced the Supreme Court and shaped the meaning of the Constitution. Nova York: Farrar, Straus and Giroux, 2009.
}

com as cortes inferiores; iv) as interações entre os poderes; e v) a opinião pública. ${ }^{39}$

Em que pese estas críticas à supremacia judicial, o argumento da deferência do Poder Judiciário ao Legislativo ignora a diferenciação entre as questões procedimentais e as questões substanciais (relativas ao conteúdo) da decisão do legislador. ${ }^{40}$ André Del Negri explica que na análise da possibilidade do controle de constitucionalidade sobre as questões interna corporis é necessário fazer distinção entre: "o mérito das decisões do Congresso (mérito político), e os procedimentos (regimentos internos) que os projetos de lei têm que seguir". ${ }^{41}$

Thomas Bustamante explica que o argumento da crítica à supremacia judicial nada tem a ver com a possiblidade de intervenção judicial para garantir a regularidade do processo legislativo. ${ }^{42}$ As críticas a expansão jurisdicional se direcionam sobretudo ao ativismo substancialista, ou seja, a atuação exagerada do Judiciário na definição do conteúdo e sentido das normas constitucionais. ${ }^{43}$

De fato, a crítica à supremacia judicial só faz sentido se houver confiança no processo legislativo democrático:

O núcleo da crítica à supremacia judicial está justamente na confiança que os críticos depositam no processo legislativo, que funcionaria com uma espécie de filtro ou catalizador do debate

40 BUSTAMANTE, Thomas da Rosa; BUSTAMANTE, Evanilda Nascimento de Godoi. Jurisdição Constitucional na era cunha: entre o passivismo procedimental e o ativismo substancialista do Supremo Tribunal Federal. Revista Direito \& Práxis. Rio de Janeiro, v. 07, n. 13, 2016. p. 364. ${ }^{41}$ NEGRI, André del. Processo Constitucional e decisão interna corporis. Belo Horizonte: Fórum, 2011. p. 96.

42 BUSTAMANTE, Thomas da Rosa; BUSTAMANTE, Evanilda Nascimento de Godoi. Jurisdição Constitucional na era cunha: entre o passivismo procedimental e o ativismo substancialista do Supremo Tribunal Federal. Revista Direito \& Práxis. Rio de Janeiro, v. 07, n. 13, 2016. p. 364.

${ }^{42}$ NEGRI, André del. Processo Constitucional e decisão interna corporis. Belo Horizonte: Fórum, 2011. p. 364. ${ }^{43}$ Ibid, p. 364. 
constitucional e permitiria - caso levado a sério pelos participantes em suas deliberações - uma deliberação capaz de tomar em conta os argumentos, interesses e direitos de cada um dos grupos e indivíduos representados no debate parlamentar. Não faz sentido qualquer crítica à supremacia judicial sem uma garantia de que o processo legislativo seja rigorosamente observado. ${ }^{44}$

Um dos principais argumentos contra a supremacia judicial vem de Jeremy Waldron e Richard Bellamy. Segundo Waldron, a doutrina jurídica contemporânea idealizou o poder jurisdicional e ao mesmo tempo marginalizou o Legislativo. ${ }^{45}$ Nesta visão, enquanto os magistrados são virtuosos e racionais, o legislador vive de negociatas, barganhas e concessões. ${ }^{46}$

Mangabeira Unger afirma que teoria jurídica contemporânea tem um "segredinho sujo" 47 que é o seu desconforto com a democracia. ${ }^{48}$ Para Unger, a desconfiança com a democracia se apresenta em todas áreas da cultura jurídica contemporânea:

[...] in the ceaseless identification of restraints upon majority rule, rather than of restraints upon the power of dominant minorities, as the overriding responsibility of judges and jurists; in the consequent hypertrophy of countermajoritarian practices and arrangements; in the opposition to all institutional reforms, particularly those designed to heighten the level of popular political enagagement, as threats to a regime of rights; in the equation of the rights of property with the rights of dissent; in the effort to obtain from judges, under the cover of improving interpretation, the advances popular politics fail to deliver; in the abandonment of institutional reconstruction to rare and magical moments of national refoundation; in the single-minded focus upon the higher judges and their selection as the most important part of democratic politics; in an ideal of

\footnotetext{
${ }^{44}$ Ibid, p. 364.

45 WALDRON, Jeremy. Law and Disagreement. New York: Oxford University Press, 1999. p. 8.

${ }^{46}$ PAULINO, Lucas Azevedo. Jurisdição Constitucional sem supremacia judicial: a reconciliação entre a proteção de direitos fundamentais e a legitimidade democrática no constitucionalismo. 2016. 177 f. Dissertação (Mestrado em Direito)-Universidade Federal de Minas Gerais, Belo Horizonte, 2016. p. 58.

${ }^{47}$ Tradução livre de: "dirty little secret".

48 UNGER, Roberto Mangabeira. What Should Legal Analysis become? Londres: Verso, 1996. p. 72
}

deliberative democracy as most acceptable when closest in style to a polite conversation among gentlemen in an eighteenth-century drawing room; and, occasionally, in the explicit treatment of party government as a subsidiary, last-ditch source of legal evolution, to be tolerated when none of the more refined modes of legal resolution applies. ${ }^{49}$

Para Waldron e Bellamy, as decisões judiciais são eivadas de um déficit democrático. Ambos os autores partem do pressuposto que existem desacordos morais razoáveis sobre o conteúdo das normas e que o processo democrático tem mais legitimidade do que o processo judicial para resolver estes desacordos. ${ }^{50}$ $\mathrm{Na}$ opinião deles, os indivíduos divergem entre si, ao ponto que o único acordo possível é estabelecer um processo isonômico de tomada de decisão. $\mathrm{E}$ nesse contexto que o processo legislativo democrático se torna fundamental. ${ }^{51}$

Marcelo Cattoni explica que no Estado Democrático de Direito, a jurisdição constitucional tem as tarefas: de garantia do devido processo legislativo democrático e de garantia do devido processo constitucional. ${ }^{52}$

Ante a importância do Processo Legislativo, é papel da Corte Constitucional tutelar as regras do jogo democrático, sobretudo assegurar as formas que regem o processo legislativo. Nesse sentido, o controle procedimental do processo legislativo pelo Supremo Tribunal Federal se torna fundamental.

Observa-se que a recusa da jurisdição constitucional em analisar as questões procedimentais do processo legislativo pode

49 UNGER, Roberto Mangabeira. What Should Legal Analysis become? Londres: Verso, 1996. p. 73

50 BELLAMY, Richard. Political Constitucionalism: a republican defence of the constitutioanlity of democracy. Cambrige: Cambridge University Press, 2007.

51 BUSTAMANTE, Thomas da Rosa; BUSTAMANTE, Evanilda Nascimento de Godoi. Jurisdição Constitucional na era cunha: entre o passivismo procedimental e o ativismo substancialista do Supremo Tribunal Federal. Revista Direito \& Práxis. Rio de Janeiro, v. 07, n. 13, 2016. p. 352.

52 CATTONI, Marcelo. Devido processo legislativo. 2. ed. Belo Horizonte: Mandamentos, 2006. p. 167. 
acarretar graves consequências para o estado democrático de Direito.

É possível relacionar essas conclusões teóricas com o problema do manejo de emendas aglutinativas no processo legislativo e o passivismo procedimental do Supremo Tribunal assentado no julgamento do Mandado de Segurança $n^{\circ} 22.503$.

\section{CRÍTICA AO PASSIVISMO PROCEDIMENTAL ADOTADO PELO SUPREMO TRIBUNAL FEDERAL NO JULGAMENTO DO MANDADO DE SEGURANÇA $\mathbf{N}^{\circ} \mathbf{2 2 . 5 0 3}$}

O professor Thomas Bustamante ao analisar as polêmicas recentes sobre a Proposta de Emenda Constitucional $\mathrm{n}^{\circ}$ 182/2007 (sobre a reforma política) e a PEC $\mathrm{n}^{\circ}$ 171/1993 (sobre a redução da maioridade penal) alerta que as emendas aglutinativas sucessivas favorecem $o$ autoritarismo.

Ao voltarmos para o caso concreto do julgamento da PEC no 33/95 que tinha como objeto a modificação do sistema da Previdência Social, a discussão principal que envolve a questão é se a emenda aglutinativa poderia ter sido apresentada depois da rejeição do substitutivo. ${ }^{53}$

O Ministro Marco Aurélio enfrentou a questão ao interpretar o regimento à luz do artigo 60 da Constituição da República, mas conforme demonstrado se equivocou ao confundir o substitutivo com a proposição inicial e concluir que a emenda se trava de uma nova proposta:

Voltando ao Regimento Interno da Câmara dos Deputados, é dado constatar disciplina toda própria da forma de votação - o artigo 191 - que reclama o cotejo com a Constituição Federal. O substitutivo de

\footnotetext{
53 BUSTAMANTE, Thomas da Rosa; BUSTAMANTE, Evanilda Nascimento de Godoi. Jurisdição Constitucional na era cunha: entre o passivismo procedimental e o ativismo substancialista do Supremo Tribunal Federal. Revista Direito \& Práxis. Rio de Janeiro, v. 07, n. 13, 2016. p. 383.
}

Comissão tem preferência na votação sobre o projeto - inciso II; votar-se-á, em primeiro lugar, o substitutivo de Comissão e, havendo mais de um, a preferência será regulada pela ordem inversa de sua apresentação - inciso III; aprovado o substitutivo, ficam prejudicados o projeto e as emendas a este oferecidas, ressalvadas as emendas ao substitutivo e todos os destaques - inciso IV; na hipótese de rejeição do substitutivo, ou na votação de projeto sem substitutivo, a proposição inicial será votada por último, depois das emendas que lhe tenham sido apresentadas - inciso $\mathrm{V}$; a rejeição do projeto prejudica das emendas a ele oferecidas - inciso VI. Depreende-se desses dispositivos que a Câmara dos Deputados a eles deu aplicação. Rejeitando o substitutivo, passou-se, muito embora com interregno, e não em sequência com cobrado no artigo 181 do Regimento Interno, ao exame do que a Norma Interna rotula como "emenda aglutinativa" resultado de outras emendas ou desta com o texto, por transação tendentes à aproximação dos respectivos objetos. Ocorre que a apreciação da emenda aglutinativa pressupõe a ausência de votação da proposta inicial que tenha provocado a apresentação das emendas aglutinadas. Tanto é assim que o Regimento Interno preceitua que 'as emendas aglutinativas podem ser apresentadas em Plenário, para apreciação em turno único, quando da votação da parte da proposição ou do dispositivo a que elas se refiram, pelos Autores das emendas objeto da fusão, por um décimo dos membros da Casa ou por Líderes que representem este número' (artigo 122, caput). Quando apresentadas pelos autores, a emenda aglutinativa implica a retirada das emendas das quais resulta. Essa é a única interpretação harmônica com as normas constitucionais que, relativamente aos projetos de lei e, no caso específico, a proposta de emenda constitucional, vedam a apreciação na mesma sessão legislativa artigos $60, \S 5^{\circ}$, e 67 , notando-se, em relação a este último, a abertura de vir-se a apreciar a mesma matéria no curso da sessão legislativa, caso ocorra a formalização de proposta por maioria absoluta dos membros de qualquer das Casas do Congresso Nacional. Ora, no caso, procedeu-se à apreciação de emenda aglutinativa quando já apreciada e rejeitada a proposição inicial. Mais do que isso, implementouse a prática em data diversa daquela em que teve início a votação. ${ }^{54}$

\section{O professor Thomas Bustamante ressaltou} que o momento da apresentação da emenda

54 BRASIL. Supremo Tribunal Federal. Mandado de Segurança $\mathrm{n}^{\circ}$ 22.503. Relator: Relator Ministro Marco Aurélio, Relator para o Acórdão Ministro Maurício Corrêa. Brasília, DF, 08 de maio de 1996. Diário da Justiça. Brasília, 06 jun. 1997. 
aglutinativa deve ser respeitado para que haja compatibilização entre a norma regimental e o art. $60, \S 5^{\circ}$, da Constituição da República:

De outro lado, esta interpretação estabelece uma condição que é estritamente necessária para a observância do art. $60, \S 5^{\circ}$, da Constituição: a exigência de que todas as emendas, aglutinativas ou não, sejam propostas antes do início da votação, de modo que o Plenário esteja ciente de cada uma das alternativas que estão na mesa, e cada parlamentar possa refletir sobre elas sem o risco de surpresas após o resultado da votação e sem a possibilidade, ainda mais grave, de sofrer pressão política para mudar o seu voto, depois da divulgação do resultado das votações nominais. ${ }^{55}$

A maioria do Supremo Tribunal Federal se omitiu ao não interpretar o Regimento Interno conforme o $\$ 5^{\circ}$ do artigo 60 da Constituição da República.

O artigo 60 da Constituição da República revela a opção do constituinte originário pela rigidez constitucional, estabelecendo limites ao poder de reforma e exigindo um ato complexo quórum qualificado de três quintos, em dois turnos de votação em cada Casa do Congresso Nacional.

$\mathrm{O} \S 5^{\circ}$ do artigo 60 é classificado como limitação de reapreciação ao poder de reforma da Constituição. ${ }^{56} \mathrm{~A}$ previsão constitucional é uma limitação procedimental a fim de dar segurança e estabilidade jurídica ao processo legislativo, conforme ficou registrado no voto do Ministro Marco Aurélio ao citar o artigo do Senador Josaphat Marinho:

\footnotetext{
${ }^{55}$ BUSTAMANTE, Thomas da Rosa; BUSTAMANTE, Evanilda Nascimento de Godoi. Jurisdição Constitucional na era cunha: entre o passivismo procedimental e o ativismo substancialista do Supremo Tribunal Federal. Revista Direito \& Práxis. Rio de Janeiro, v. 07, n. 13, 2016. p. 382. ${ }^{56}$ COSTA, Nelson Nery. Constituição Federal anotada e explicada. 5. ed. rev., atual. e ampl. Rio de Janeiro: Forense, 2012. p. 270.

57 BRASIL. Supremo Tribunal Federal. Mandado de Segurança $\mathrm{n}^{\circ}$ 22.503. Relator: Relator Ministro Marco Aurélio, Relator para o Acórdão Ministro Maurício Corrêa.
}

A finalidade superior da norma constitucional é obrigar à reflexão, coibindo julgamento contraditórios, prejudiciais ao Poder Legislativo e à segurança dos direitos das pessoas em geral. Enfim, o que está prudentemente recomendado é que o legislador não deve mudar de ideia em prazo curto $\mathrm{e}$ sem razão convincente. A recomendação é compreensível e correta, porque essa mudança brusca o enfraquece na opinião pública e pode ofender a estabilidade das relações jurídicas. ${ }^{57}$

As limitações do artigo 60 impedem que a Constituição fique a mercê de situações circunstanciais excepcionais e permitem pela rigidez proporcionar uma maior estabilidade constitucional. ${ }^{58}$

A interpretação do Regimento Interno conforme a Constituição impede que a regulamentação interna da Câmara seja utilizada para violar a previsão constitucional.

O professor Thomas Bustamante fez o alerta sobre esta situação, denunciando o passivismo do Supremo Tribunal Federal no julgamento do Mandado de Segurança n ${ }^{\circ} 22.503-$ 3:

\begin{abstract}
Sem essa interpretação, a Presidência da Casa pode viabilizar a votação de emendas aglutinativas sucessivas, até que uma delas seja atinja o quórum necessário de aprovação e a sua proposta seja vencedora. Se aliarmos a isso um processo de votação nominal, como ocorre em quase todas as matérias polêmicas, abre-se a via para um mecanismo autoritário e eficaz de controle sobre o resultado das votações, na medida em que é possível saber exatamente quais parlamentares votaram contra e a favor do projeto original. Cria-se, portanto, um contexto político e institucional que alimenta e favorece o autoritarismo no interior das Casas legislativas. ${ }^{59}$
\end{abstract}

Brasília, DF, 08 de maio de 1996. Diário da Justiça. Brasília, 06 jun. 1997. p. 524.

${ }^{58}$ SARLET, Ingo W.; BRANDÃO, Rodrigo. Comentário ao artigo 60. In: CANOTILHO, J. J. Gomes; MENDES, Gilmar F.; STRECK, Lenio L. (Coord.). Comentários à Constituição do Brasil. São Paulo: Saraiva/Almedina, 2013. p. 2631.

${ }^{59}$ BUSTAMANTE, Thomas da Rosa; BUSTAMANTE, Evanilda Nascimento de Godoi. Jurisdição Constitucional na era cunha: entre o passivismo procedimental e o ativismo substancialista do Supremo Tribunal Federal. Revista Direito \& Práxis. Rio de Janeiro, v. 07, n. 13, 2016. p. 382. 


\section{CONCLUSÃO}

Após vinte e um anos do julgamento do Mandado de Segurança $n^{\circ}$ 22.503-3/DF, as discussões que envolvem o manejo das emendas aglutinativas no processo legislativo brasileiro vieram à tona após a aprovação das Propostas de Emenda à Constituição $n^{\circ}$ 182/2007 (Reforma Política) e no 171/1993 (redução da maioridade penal) na Câmara dos Deputados, que ocasionaram a impetração dos Mandados de Seguranças $\mathrm{n}^{\circ} 33.630$ e 33.697 por diversos parlamentares perante o Supremo Tribunal Federal.

As polêmicas atuações do ex-Presidente da Câmara, Deputado Eduardo Cunha, reacendeu a discussão em torno da postura passiva do Supremo Tribunal Federal em relação às questões procedimentais.

Demonstramos que embora haja um discurso oficial da jurisprudência do Supremo Tribunal Federal de deferência ao Poder
Legislativo em relação às questões interna corporis em razão do problema da supremacia judicial, vimos que essas críticas não são direcionadas ao controle procedimental do processo legislativo

Nesse sentido, defendemos que, apesar da desconfiança em relação supremacia judicial, é papel da Corte Constitucional tutelar as regras do jogo democrático, sobretudo assegurar as formas que regem o processo legislativo.

Assim, apontamos que ao não interpretar o Regimento Interno da Câmara dos Deputados à melhor luz da Constituição da República, o Supremo Tribunal Federal estabeleceu uma jurisprudência que permite que o Regimento Interno da Câmara dos Deputados pudesse ser utilizado de forma autoritária e arbitrária, como no caso da apresentação de Emendas Aglutinativas sucessivas, o que gera uma instabilidade no Processo Legislativo, violando a limitação constitucional prevista no artigo $60, \S 5$, da Constituição da República.

\section{REFERÊNCIAS}

BARROSO, Luís Roberto. Constituição, democracia e supremacia judicial: direito e política no Brasil contemporâneo. RFD - Revista da Faculdade de Direito - UERJ, v.2, n. 21, jan./jun. 2012.

BARROSO, Luís Roberto. $O$ controle de constitucionalidade no direito brasileiro: exposição sistemática da doutrina e análise crítica da jurisprudência. 6. ed. São Paulo: Saraiva, 2012.

BELLAMY, Richard. Political Constitucionalism: a republican defence of the constitutioanlity of democracy. Cambrige: Cambridge University Press, 2007.

BICKEL, Alexander M. The least dangerous branch: the supreme court at the bar of politics. Indianapolis, New York: The Bobbs-Merrill Company, 1962.

BRANDÃO, Rodrigo. Supremacia judicial versus diálogos institucionais: a quem cabe a última palavra sobre o sentido da constituição. Rio de Janeiro: Lumen Juris, 2012.

BRASIL. Constituição (1988). Palácio do Planalto, Brasília. Disponível em: <http://www.planalto.gov.br/ccivil_03/constituicao/constituicaocompilado.htm>. Acesso em: 05 mai. 2017. 
BRASIL. Congresso Nacional. Câmara dos Deputados. Regimento interno da Câmara dos Deputados [recurso eletrônico]. 15. ed. Brasília: Câmara dos Deputados, Edições Câmara, 2015. (Série textos básicos, n. 103).

BRASIL. Resolução $n^{o} 93$ de 1970 do Senado Federal. Dá nova redação ao Regimento Interno do Senado Federal.

BRASIL. Supremo Tribunal Federal. Mandado de Segurança ${ }^{\circ}$ 22.503. Relator: Relator Ministro Marco Aurélio, Relator para o Acórdão Ministro Maurício Corrêa. Brasília, DF, 08 de maio de 1996. Diário da Justiça. Brasília, 06 jun. 1997.

BRASIL. Supremo Tribunal Federal. Mandado de Segurança ${ }^{\circ}$ 20.257. Relator: Ministro Décio Miranda, relator para acórdão Ministro Moreira Alves. Brasília, 08 de outubro de 1980. Diário da Justiça. Brasília, 27 fev. 1981.

BRASIL. Supremo Tribunal Federal. Ação Direta de Inconstitucionalidade $n^{\circ} 4.425$, Distrito Federal. Relator: MInistro Ayres Brito, redator para Acórdão Ministro Luiz Fux. Brasília, 14 de março de 2013. Diário da Justiça Eletrônico. Brasília, 19 dez. 2013.

BUSTAMANTE, Thomas da Rosa. Emendas aglutinativas sucessivas favorecem o autoritarismo. Consultor Jurídico. 02 out. 2015.

BUSTAMANTE, Thomas da Rosa; BUSTAMANTE, Evanilda Nascimento de Godoi. Jurisdição Constitucional na era cunha: entre o passivismo procedimental e o ativismo substancialista do Supremo Tribunal Federal. Revista Direito \& Práxis. Rio de Janeiro, v. 07, n. 13, 2016.

CANOTILHO, J. J. Gomes; MENDES, Gilmar F.; SARLET, Ingo W.; STRECK, Lenio L. (Coord.). Comentários à Constituição do Brasil. São Paulo: Saraiva/Almedina, 2013.

CATTONI, Marcelo. Devido processo legislativo. 2. ed. Belo Horizonte: Mandamentos, 2006.

COSTA, Nelson Nery. Constituição Federal anotada e explicada. 5. ed. rev., atual. e ampl. Rio de Janeiro: Forense, 2012.

FRIEDMAN, Barry. The politics of judicial review. New York University Public Law and Legal Theory Working Papers. Paper 16. 2006. Disponível em: <http://lsr.nellco.org/nyu_plltwp/16>. Acesso em: 05 mai. 2017.

The will of the people: how public opinion has influenced the Supreme Court and shaped the meaning of the Constitution. Nova York: Farrar, Straus and Giroux, 2009.

HORBACH, Carlos Bastide. Por que a aprovação da PEC da maioridade penal é constitucional. Consultor Jurídico. 05 jul. 2015.

MENDES, Gilmar Ferreira; BRANCO, Paulo Gustavo Gonet. Curso de direito constitucional. 9. ed. rev. e atual. São Paulo : Saraiva, 2014.

NEGRI, André del. Processo Constitucional e decisão interna corporis. Belo Horizonte: Fórum, 2011. $136 \mathrm{p}$. 
PAULINO, Lucas Azevedo. Jurisdição Constitucional sem supremacia judicial: a reconciliação entre a proteção de direitos fundamentais e a legitimidade democrática no constitucionalismo. $2016.177 \mathrm{f}$. Dissertação (Mestrado em Direito)-Universidade Federal de Minas Gerais, Belo Horizonte, 2016.

SARLET, Ingo W.; BRANDÃO, Rodrigo. Comentário ao artigo 60. In: CANOTILHO, J. J. Gomes; MENDES, Gilmar F.; STRECK, Lenio L. (Coord.). Comentários à Constituição do Brasil. São Paulo: Saraiva/Almedina, 2013. p. 2631.

SARMENTO, Daniel; NETO, Cláudio Pereira de Souza. Notas sobre jurisdição constitucional e democracia: a questão da "última palavra" e alguns parâmetros de autocontenção judicial. Revista Quaestio Iuris, v. 6, n. 2. ISSN 1516-0351.

SULTANY, N. The State of Progressive Constitutional Theory: The Paradox of Constitutional Democracy and the Project of Political Justification. Harvard Civil Rights - Civil Liberties Law Review, 47/2012.

SUNSTEIN, Cass R; VERMEULE, Adrian. Interpretation and institutions. John M. Olin Program in Law and Economics Working Paper No. 156, 2002.

UNGER, Roberto Mangabeira. What Should Legal Analysis become? Londres: Verso, 1996.

WALDRON, Jeremy. Law and Disagreement. New York: Oxford University Press, 1999.

WALDRON, Jeremy. The core of the case against judicial review. Yale Law Journal, v. 115, p. 13461406, 2006.

Recebido em: 05/05/2017

Aceito em: 06/07/2017 
